\title{
Spinal Deformity Surgery : It Becomes an Essential Part of Neurosurgery
}

\author{
Seung-Jae Hyun, M.D., Ph.D., Jong-myung Jung, M.D. \\ Department of Neurosurgery, Spine Center, Seoul National University Bundang Hospital, Seoul National University College of Medicine, Seongnam, \\ Korea
}

Among the spinal disorders, the treatment approach for spinal deformities has been discussed least among department of neurosurgery. But nowadays, more and more neurosurgeons are interested in spinal deformities as well as complex spinal disorders and are doing not a few surgeries for these kinds of disease. Nevertheless, it is mandatory to understand the course of spinal deformity, principles of treatment, and surgical outcomes and complications. Understanding of the biology, biomechanics and metallurgy of the spine and instrumentation are also required for successful spinal deformity surgery. We need senior mentors and good surgical and neurophysiologic monitoring team. Knowledge of spinal deformity may be augmented with spine fellowships and surgical experience. Step by step training such as basic knowledge, orthopedic as well as neurosurgical disciplines and surgical skills would be mandatory. Neurosurgeons can have several advantages for spinal deformity surgeries. By high-level technical ability of the spinal cord handling to preserve neurological function and familiarity with microscopic surgery, better synergistic effect could be expected. A fundamental understanding of pediatric spinal deformity and growing spine should be needed for spinal deformity surgery.

Key Words : Scoliosis · Instrumentation · Spinal deformity · Neurosurgeon · Outcomes.

\section{INTRODUCTION}

Spinal deformity surgery is increasing in modern spine surgery practice ${ }^{33}$. As the average life expectancy increased and population aging progresses, the number of patients requiring spinal deformity surgery will continue to increase ${ }^{34}$. The prevalence of spinal deformity was reported to be over $65 \%$ in the population older than 60 years ${ }^{33}$. Spinal deformity causes pain and disability. Patients having spinal deformity experience poor health related quality of life ${ }^{3)}$.
Spinal surgery was a small part of neurosurgery, but it now accounts for most of neurosurgery ${ }^{2}$. Furthermore, spinal deformity surgery was rarely performed by neurosurgeons. However, neurosurgeons have gradually learned knowledge and experienced spinal deformities such as congenital and adolescent scoliosis with great interest and active participation $^{8,19,27)}$. Nowadays, neurosurgeons are evaluating patients with spinal deformity, but the treatment of spinal deformity was not as proficient as other spinal disease. It was because there was less opportunity to see patients with spinal deformi-

- Received : July 9, 2018 •Accepted : July 27, 2018

- Address for reprints : Jong-myung Jung, M.D.

Department of Neurosurgery, Spine Center, Seoul National University Bundang Hospital, Seoul National University College of Medicine, 82 Gumi-ro 173beon-gil, Bundang-gu, Seongnam 13620, Korea

Tel : +82-31-787-6293, Fax : +82-31-787-4097, E-mail : beast2625@snu.ac.kr

This is an Open Access article distributed under the terms of the Creative Commons Attribution Non-Commercial License (http://creativecommons.org/licenses/by-nc/4.0) which permits unrestricted non-commercial use, distribution, and reproduction in any medium, provided the original work is properly cited. 
ties during residency or fellowship. Because of the complex nature of spine deformity, comprehensive knowledge of spinal anatomy, natural history of the disease and indication for surgery should be included in the training course of spinal surgeons ${ }^{7}$. Otherwise, the surgical- and clinical outcomes cannot be optimal ${ }^{31}$. Understanding of spinal deformity, biomechanics of spine and instrumentation, and neurophysiological monitoring is definitely essential. The purpose of this review is to introduce clinical and radiographic outcomes of patients with spinal deformities treated by neurosurgeons and to suggest the factors needed to perform spinal deformity surgery.

\section{OVERVIEW OF SPINAL DEFORMITY}

Spinal deformity is a complex and dynamic change that occurs in the sagittal, coronal or planes. There are two types of spinal deformity : coronal plane deformations (scoliosis) and sagittal plane deformations (kyphosis). They can appear alone or in combination. The interaction between coronal and sagittal curvature is a dynamic process. Successful treatment aims to achieve a satisfactory balance on both planes. Spinal deformity surgery is a complicated operation with a high frequency of complications. The primary goal of deformity surgery is to achieve a balanced spinal alignment through rigid fusion, prevent further deformity and alleviate neurological symptoms. A secondary goal of spinal deformity surgery is to improve appearance for cosmetic purpose.

Some patients with spinal deformity are treated conservatively or palliative care, such as medications, braces, and exercises. Other deformity patients may undergo limited decompression and fusion surgeries. The main indication for adult spinal deformity surgery is severe pain associated with the curve progression. The character of the pain may be axial back pain, radiating pain or a combination ${ }^{38)}$. Other indications are progression of the deformed curve and spinal decompensation. In the adolescent patients, deformity progression and cosmetic factor (poor appearance) are the most common indications for spinal deformity surgery. Decreased pulmonary function is also indicated for spinal deformity surgery $y^{4)}$.

\section{SURGICAL RESULTS AND COMPLICATIONS}

The success of spinal deformity surgery depends on patients' satisfaction after surgical intervention. Patient satisfaction after spinal deformity surgery was approximately $90 \%{ }^{4}$. In several studies using the Scoliosis Research Society outcome measurement questionnaire (SRS-22), the satisfaction with their surgical outcome was reported between 76 and $92 \%{ }^{12}$. In the study using the Short Form (SF)-36 outcomes measurement, pain was significantly decreased and physical and social function were significantly increased after spinal deformity surgery ${ }^{1)}$.

In adults, curve correction is approximately 20 degrees and 26 degrees for coronal plane by surgery ${ }^{12}$. Because the rigidity of spine, the degree of curve correction in adult patients may be lower than that in pediatric patients. Overcorrection of the coronal curve may result in decompensation and a poor clinical outcome. The goal of adult deformity surgery is not just to correct the degree of the curve, but to achieve a balanced spine.

The complication rate of spinal deformity surgery is rather high. The incidence of complication is about $33 \%{ }^{12}$. Due to more rigid curves and underlying medical condition, the incidence of complications associated with spinal deformity surgery is higher in adults than in adolescents ${ }^{37,39)}$. Complications associated with pedicle subtraction osteotomy (PSO) are relatively common. Case series treated by a senior neurosurgeon demonstrated that eight of 13 patients (61\%) who underwent PSO were associated with complications ${ }^{17)}$. There were three intra-operative complications (two massive bleeding, one dural tear), three peri-operative complications (one spinal cord compression, one cerebrospinal fluid leakage, one hypotension), and 10 late-onset postoperative complications (five rod fracture, three proximal junctional kyphosis [PJK] without adjacent segment collapse, one progression of kyphosis with collapse, one haloing around screw). Four of them underwent additional surgery. Neurologic deficits associated with PSO are also relatively common. Twelve of 108 patients (11.1\%) developed neurologic deficit ${ }^{6}$. Additional surgical intervention was performed in nine of them. However, neurological deficits were permanent in three patients (2.8\%). Perioperative mortality was reported as $2 \%{ }^{23)}$. The prevalence of PJK following spinal deformity surgery was 17 to $39 \%{ }^{18)}$. 


\section{BIOMECHANICS OF THE SPINE AND INSTRU- MENTATION}

As knowledge of the spine increases, it is clear that the biomechanical basis is essential for the prevention and treatment of spinal disease. Biomechanics provides a way to quantitatively and accurately assess the condition of the spine and evaluate its characteristics. Biomechanical evaluation helps to understand the potential pathways of spinal disease and to understand how the surgeon can influence the health of the spine. As the understanding of the spine has increased over the past decade, neurosurgeons have received many new technologies and opportunities. However, most spinal implant failures are due to iatrogenic factors such as inappropriate patient selection, underestimation of stresses, and poor construct design $^{32}$.

PJK and proximal junctional failure (PJF) are complications that can occur after long instrumented posterior fusion for spinal deformity surgery ${ }^{18)}$. Strategies to minimize PJK and PJF are as follow : age-appropriate spinopelvic alignment goals, adequate selection of the upper instrumented vertebrae (UIV), vertebral cement augmentation at UIV and UIV+1, adequate selection of rod material, hybrid instrumentation such as hooks, prophylactic rib fixation and soft tissue protections ${ }^{15)}$. Understanding the biomechanics and instrumentation may reduce as the incidence of PJK and PJF. The use of multiple rod construct (multi-RC) enhances the stability of the 3-column osteotomy site and reduces implant failure and symptomatic pseudarthrosis compared to $2-\mathrm{RC}^{16)}$. There were significant decrease in the incidence of rod fracture (2-RC, 11; multi-RC, $2 ; p=0.002)$ and reoperation for pseudarthrosis (2$\mathrm{RC}, 6$; multi-RC, $0 ; p=0.011)$. The incidence of PJK was higher in the multi-RC group than in the 2-RC group, but there was no significant difference $(p=0.77)$. The use of cobalt chrome $(\mathrm{CoCr})$ rods increases fusion rate and enhances spinal stabili$\mathrm{ty}^{13)}$. The fusion rate of CoCr rod group was significantly higher than that of titanium (Ti) rod group $(90 \%$ and $66 \%$, respectively; $p=0.004$ ). The incidence of rod fracture of $\mathrm{CoCr}$ rod group was significantly lower than that of Ti rod group ( $0 \%$ and $16 \%$, respectively; $p=0.006$ ). However, PJK occurred more frequently in $\mathrm{CoCr}$ rods than in Ti rods with significant difference ( $46 \%$ and $18 \%$, respectively; $p=0.003$ ).

\section{INTRAOPERATIVE NEUROMONITORING IN SPI- NAL DEFORMITY SURGERY}

Intraoperative neurophysiology monitoring is essential for spinal deformity surgery. Understanding of the pathophysiology of monitored signals of neurophysiological signal changes and anesthetic effects prevent permanent neurological deficits by enabling early detection and intervention of potential injuries.

Spinal contusions induces amplitude suppression (50-75\%) of motor evoked potential (MEP) and/or somatosensory evoked potential (SSEP) which should be resolved within approximately 15-25 minutes. Recovery from these changes is generally helps by stopping additional surgical maneuvers temporarily and by increasing mean arterial blood pressure to promote improved spinal cord perfusion. More severe injury, such as that caused by an uncontrolled surgical instrument such as drill or osteotome may completely obliterate both MEP and SSEP ${ }^{36)}$.

The speed of corrective manipulation may cause spinal cord injury. This is especially important for hemodynamic management. Slow corrective manipulation with maintenance of mean arterial blood pressure near normal blood pressure compensates for changes in spinal cord perfusion pressure and allows the spinal cord to adapt to the changed environment. Prolonged hypotension may cause spinal cord isch$\mathrm{emia}^{5}$. To minimize ischemic spinal cord injury, prevention of hypotension is recommended once the spine is exposed.

\section{TRAINING BACKGROUND BETWEEN NEURO- SURGEON AND ORTHOPEDIC SURGEON}

Before assessing the ability of neurosurgeons to perform spinal deformity surgery, we analyzed the differences between neurosurgeons and orthopedic surgeons in spine fields. Previous studies have demonstrated that surgeons with either training background can achieve similar results and have similar competence when treating common spinal pathologies ${ }^{35}$.

The neurosurgeons felt more competent in the upper cervical surgery, myelopathy and spinal cord tumors ${ }^{30)}$. The orthopedic surgeons felt the same in spinal deformity, pelvic trauma. Despite guidelines for training are similar in neurosurgery and orthopedics, experiences during their training are clearly 
different in terms of exposure to spinal deformity. Neurosurgeons experience only two spinal deformity cases during residency on average, compared to an average 9.5 for orthopedic residents ${ }^{11)}$.

\section{IMPACT OF EDUCATION, TRAINING AND PRAC- TICE EXPERIENCE}

There are strength and weakness for spinal deformity knowledge base within the neurosurgical training program or practice. A survey of American association of neurological surgeons membership assessed the deformity knowledge base and impact of training and practice experience ${ }^{10}$. Completion of a spine fellowship, more than 10 years in practice, and more than $75 \%$ spine practice had a high percentage of correction answers overall $(p<0.001)$. In the completion of a spine fellowship group and more than $75 \%$ spine practice group, the percentage of correct answer was significantly higher in all categories. The group with more than 10 years in practice had a significantly higher percentage of correct answers in four of five areas. Knowledge can be increased with spinal surgery fellowships, neurosurgical experience, and spinal specialization.

European studies have also shown the importance of the fellowship training ${ }^{20)}$. The study showed that the greatest differences according to the completing of the fellowship training were the theory and practical knowledge of the management of spinal deformity in both orthopedic surgeons and neurosurgeons.

Table 1. Radiographic outcomes after PSO for fixed sagittal imbalance patients by a neurosurgeon ${ }^{28)}$

\begin{tabular}{lccc}
\hline & Pre-operative & Last F/U & p-value \\
\hline PSO angle ${ }^{*}\left({ }^{\circ}\right)$ & $5.3 \pm 10.6$ & $-25.8 \pm 11.1$ & $<0.0001^{\dagger}$ \\
\hline C7 plumb line $(\mathrm{mm})$ & $115 \pm 43$ & $32 \pm 38$ & $<0.0001^{\dagger}$ \\
\hline T5-T12 thoracic kyphosis $\left(^{\circ}\right)$ & $22.0 \pm 11.4$ & $25.5 \pm 16.3$ & 0.076 \\
T12-S1 lumbar lordosis $\left({ }^{\circ}\right)$ & $-14.1 \pm 20.5$ & $-46.3 \pm 12.8$ & $<0.0001^{\dagger}$ \\
\hline
\end{tabular}

Values are presented as mean \pm standard deviation. * The local Cobb angle measured from one level above to one level below the PSO site. ${ }^{\dagger}$ Indicates statistical significance. PSO : pedicle subtraction osteotomy, F/U : follow-up

\section{CLINICAL AND RADIOGRAPHIC OUTCOMES OF SPINAL DEFORMITY SURGERY BY NEUROSUR- GEONS}

The spinal deformity surgery performed by the neurosurgeons has been increasing, and the neurosurgeons' surgical results have been reported in several studies. Thirteen adult patients who underwent PSO for fixed sagittal imbalance ${ }^{17)}$. radiographic measurements including C7 plumb line, lumbar lordosis and PSO angle were significantly improved $(p<0.0001)$ in the long-term follow-up (Table 1). Post-operative improvement in clinical outcomes (Oswestry disability index) was significant $(p<0.001)$.

Thirty-four patients underwent posterior vertebral column resection (PVCR) for severe spinal deformity ${ }^{24}$. Radiologic and clinical outcomes following PVCR were significantly improved (Tables 2 and 3). However, two patients (5.9\%) developed transient neurological deterioration and 12 patients (35.3\%) underwent reoperation after PVCR.

PSO is a difficult and dangerous procedure that causes many complications. However, learning curve study by a neurosurgeon's series demonstrated that surgical experience has

Table 2. Pre-operative and follow-up radiographic measurements of PVCR by a neurosurgeon ${ }^{37)}$

\begin{tabular}{lccc}
\hline & Pre-operative & Last F/U & $p$-value \\
\hline VCR angle $\left(^{\circ}\right)$ & $38.4 \pm 32.1$ & $-1.7 \pm 29.4$ & $<0.001^{*}$ \\
\hline Sagittal vertical axis $(\mathrm{mm})$ & $103.6 \pm 88.5$ & $22.0 \pm 46.3$ & $<0.001^{*}$ \\
\hline Thoracic kyphosis $\left(^{\circ}\right)$ & $27.9 \pm 28.5$ & $32.1 \pm 16.2$ & 0.611 \\
\hline Lumbar lordosis $\left(^{\circ}\right)$ & $-22.1 \pm 39.1$ & $-46.3 \pm 23.8$ & $0.001^{*}$ \\
\hline Pelvic incidence $\left(^{\circ}\right)$ & $50.8 \pm 11.5$ & $50.5 \pm 10.9$ & 0.291 \\
\hline Pelvic tilt $\left(^{\circ}\right)$ & $27.2 \pm 13.5$ & $17.8 \pm 11.2$ & $0.000^{*}$ \\
\hline Sacral slope $\left(^{\circ}\right)$ & $23.6 \pm 16.0$ & $32.7 \pm 15.1$ & $0.003^{*}$ \\
\hline PI-LL $\left(^{\circ}\right)$ & $25.6 \pm 18.4$ & $11.2 \pm 10.4$ & $0.000^{*}$ \\
\hline
\end{tabular}

Values are presented as mean \pm standard deviation. ${ }^{*}$ Indicates statistical significance. PVCR : posterior vertebral column resection, F/U : followup, VCR : vertebral column resection, PI : pelvic incidence, LL : lumbar lordosis

Table 3. Pre-operative and post-operative clinical outcomes of PVCR by a neurosurgeon ${ }^{37)}$

\begin{tabular}{lccc} 
& Pre-operative & Post-operative & $\boldsymbol{p}$-value \\
\hline SRS-22 score & $2.6 \pm 0.9$ & $3.4 \pm 0.8$ & $0.033^{*}$ \\
\hline
\end{tabular}

Values are presented as mean \pm standard deviation. ${ }^{*}$ Indicates statistical significance. PVCR : posterior vertebral column resection, SRS : Scoliosis Research Society 
enabled neurosurgeons to perform PSO more proficiently and safely ${ }^{9}$. Forty patients treated with lumbar PSO were divided into two groups according to time period. There were significant reductions in operative time (from 569.6 to $392.0 \mathrm{~min}$ utes, $p=0.000$ ), estimated blood loss (from 1777.5 to $949.5 \mathrm{~mL}$, $p=0.002$ ), and transfused volume of red blood cell (from 1232.6 to $864.1 \mathrm{~mL}, p=0.041$ ) in the latter group. There were statistically significant difference in the postoperative sagittal vertical axis (40.1 and $-3.6 \mathrm{~mm}$, respectively; $p=0.008$ ) and curve correction $\left(25.7^{\circ}\right.$ vs. $\left.35.8^{\circ}, p=0.023\right)$ between the two groups. Furthermore, the incidence of intraoperative complications was significantly lower in the latter group ( 7 and 1 , respectively; $p=0.019$ ).

Forty-six patients with adolescent idiopathic scoliosis (AIS) were treated by a neurosurgeon ${ }^{14)}$. Postoperative radiologic and clinical results of AIS were satisfactory. Surgical experience allow neurosurgeon to perform surgery for AIS proficiently and safely after about 20 operations (Fig. 1). In latter 23 patients, operative time (from 324.4 to 224.7 minutes, $p=0.007$ ) and surgical bleeding (from 648.3 to $438.0 \mathrm{~mL}$, $p=0.027)$ were significantly reduced. In addition, the correction rate of the major structural curves in was also increased (from $70.7 \%$ to $81.0 \%, p=0.001$ ) in latter 23 patients.

\section{NEUROSURGEONS' ADVANTAGES FOR SPINAL DEFORMITY SURGERIES}

Neurosurgeons can have several advantages for spinal deformity surgeries. First, they have thoroughly understood about neural tissue, cerebrospinal fluid (CSF) dynamics, functional spinal neurosurgery such as selective dorsal rhizotomy (SDR) because they learned about vascular, oncologic, functional, infectious, pediatric and trauma disease ${ }^{22,25,28,29)}$. Second, they are familiar with microscopic surgery and spinal cord surgery (Fig. 2) ${ }^{21,40}$. Due to the fact that the spinal cord is essentially tethered in the canal by its confluence with the medulla oblongata and exiting nerve roots, the propensity for migration is limited once vertebral deformation develops. In the setting of a progressive kyphosis, the spinal cord will abut the posterior aspect of the vertebral bodies and disk spaces, eventually becoming draped over them if the curve becomes severe. Although the gradual nature of curve progression usually allows the spinal cord to adapt to its new position within the canal, sudden events, such as trauma or surgical correction of the deformity, can precipitate spinal cord injury. Spe-

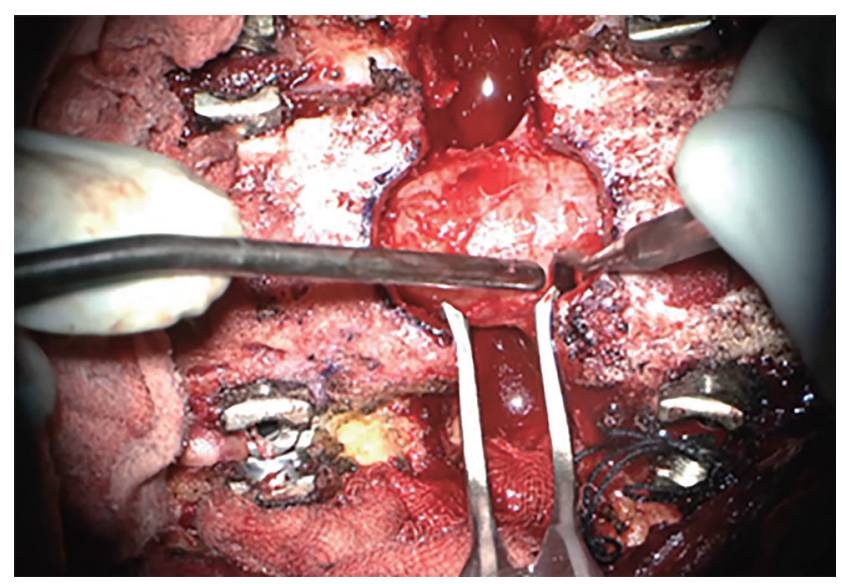

Fig. 2. Intraoperative photographs of revision pedicle subtraction osteotomy. Using a microscope, spine surgeon can perform spinal deformity surgery more safely.
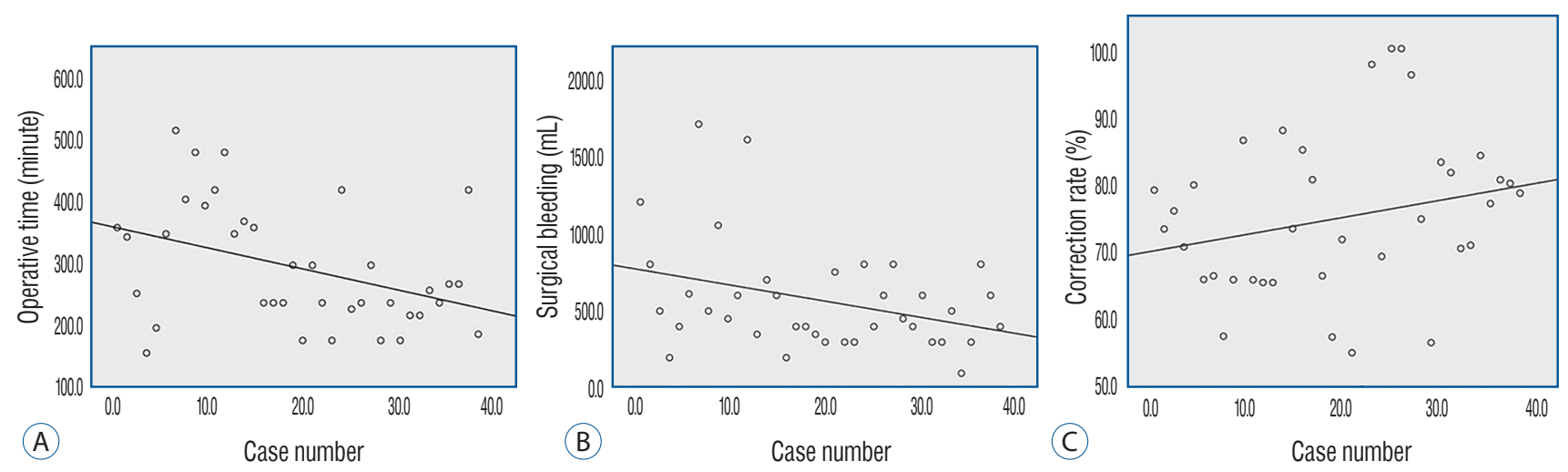

Fig. 1. Learning curve of operative time (A), surgical bleeding (B), and correction rate (C) for adolescent idiopathic scoliosis surgery by a neurosurgeon ${ }^{14)}$. 
cifically, as the spinal cord is effectively lengthened in the kyphotic process, a surgical correction may result in buckling of the cord. Scoliotic deformities can result in multiplanar deviations of the spinal cord at several levels within the medullary space. As the cord exists within a rotated spinal canal, the neurogenic structures may be more closely associated with the canal walls and pedicle on the concave side, especially at the level of the apical vertebrae. Through enhanced understanding of the spinal cord that can exist in association with deforming conditions, neurosurgeons may be better able to anticipate intraoperative difficulties and avoid complications that may adversely impact outcomes. A representative case of neuromuscular scoliosis due to cerebral palsy is summarized in Fig. 3. The patient underwent SDR and deformity corrective surgery in a single day by two attending neurosurgeons.

\section{THE KOREAN SPINAL DEFORMITY SOCIETY (KSDS)}

The KSDS was founded for researching and learning of the spinal deformity by the Korean Spinal Neurosurgical Society. The KSDS regularly holds a case presentation, academic conference and cadaver dissection training seminar every year since 2009. Spinal deformity surgery has become an essential area for spinal neurosurgeons. The members of the KSDS are actively developing their interest and participation. Especially, the interest of young neurosurgeon is explosively high. The KSDS has been studying adult spinal deformity and diseases related to various spinal deformities and provided guidelines for the treatment of spinal deformity surgery through a multicenter study $^{26)}$.

\section{CONCLUSION}

Historically, spinal deformity surgery has been performed by orthopedic surgeons. However, the role of neurosurgeon in spinal deformity continues to evolve. Completing a spine surgery fellowship will improved knowledge of spinal deformity for neurosurgeons. Furthermore, neurosurgeons can have several advantages for spinal deformity surgeries since they
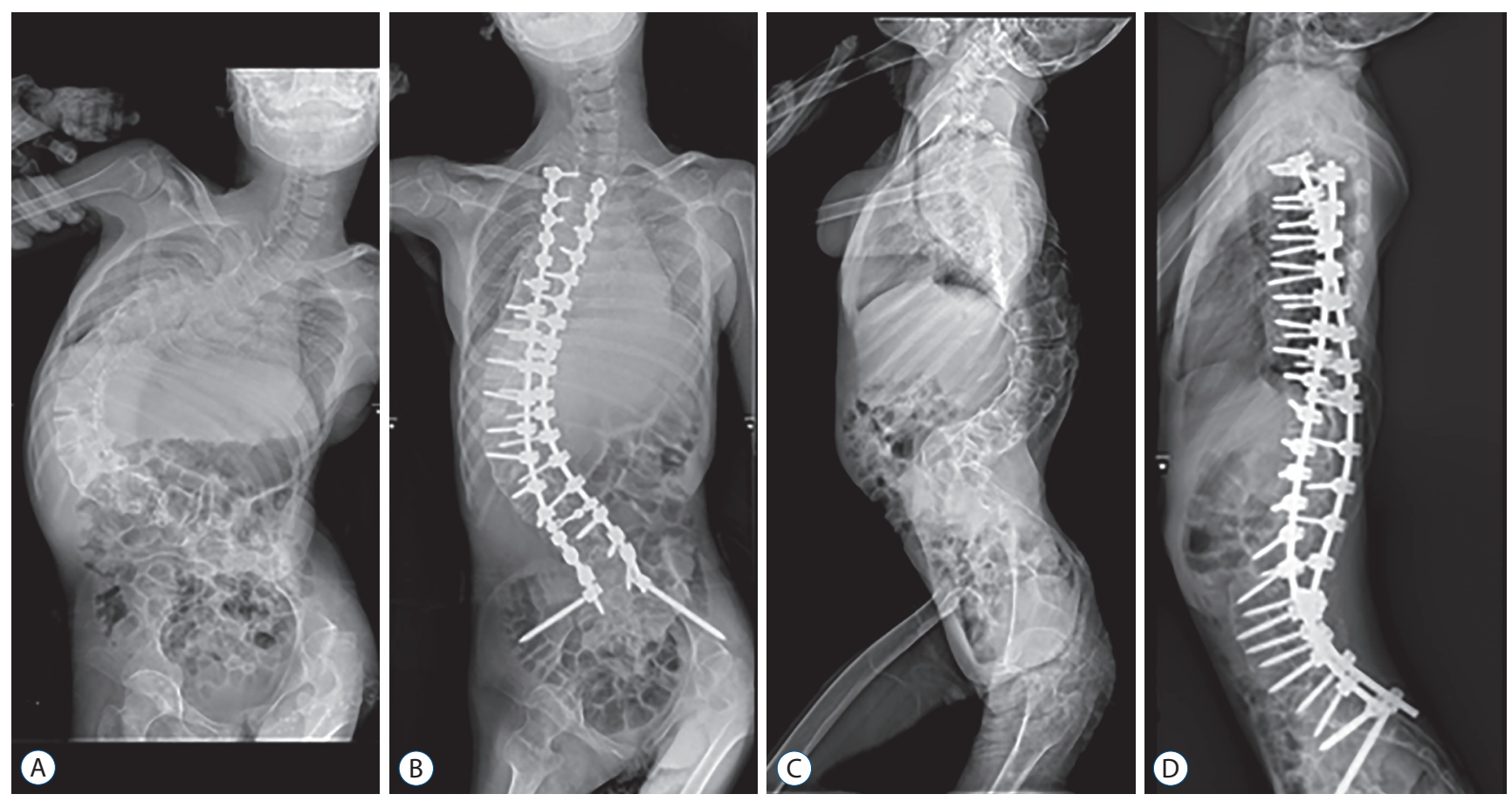

Fig. 3. Preoperative whole spine plain radiographs (A and C) showing scoliotic curvature with 150 degrees scoliosis due to cerebral palsy. Right : postoperative 6 months' whole spine plain radiographs ( $B$ and $D)$ demonstrating a balanced trunk and pelvis after surgical correction. She underwent selective dorsal rhizotomy for rigidity on her lower exteremities and deformity corrective surgery in a single day by two attending neurosurgeons. Total operative time was about 8 hours. 
have thorough understanding of neural tissue, CSF dynamics, functional spinal neurosurgery such as SDR, and they are familiar with microscopic surgery, spinal cord surgery. With knowledge and surgical experiences of spinal deformity, neurosurgeons can achieve good radiographic, surgical and clinical results in spinal deformity surgery.

\section{CONFLICTS OF INTEREST}

No potential conflict of interest relevant to this article was reported.

\section{INFORMED CONSENT}

Informed consent was obtained from all individual participants included in this study.

\section{References}

1. Albert TJ, Purtill J, Mesa J, McIntosh T, Balderston RA : Health outcome assessment before and after adult deformity surgery. A prospective study. Spine (Phila Pa 1976) 20 : 2002-2004; discussion p2005, 1995

2. Benzel EC : The evolving presence of spinal neurosurgery in the spectrum of neurological surgery. Neurosurgery $60:$ 591-592, 2007

3. Bess S, Boachie-Adjei O, Burton D, Cunningham M, Shaffrey C, Shelokov A, et al. : Pain and disability determine treatment modality for older patients with adult scoliosis, while deformity guides treatment for younger patients. Spine (Phila Pa 1976) 34 : 2186-2190, 2009

4. Bradford DS, Tay BK, Hu SS : Adult scoliosis: surgical indications, operative management, complications, and outcomes. Spine (Phila Pa 1976) 24 : 2617-2629, 1999

5. Bridwell KH, Lenke LG, Baldus C, Blanke K : Major intraoperative neurologic deficits in pediatric and adult spinal deformity patients. Incidence and etiology at one institution. Spine (Phila Pa 1976) 23 : 324-331, 1998

6. Buchowski JM, Bridwell KH, Lenke LG, Kuhns CA, Lehman RA Jr, Kim YJ, et al. : Neurologic complications of lumbar pedicle subtraction osteotomy: a 10-year assessment. Spine (Phila Pa 1976) 32 : 2245-2252, 2007

7. Cho SK, Bridwell KH, Lenke LG, Yi JS, Pahys JM, Zebala LP, et al. : Major complications in revision adult deformity surgery: risk factors and clinical outcomes with 2- to 7-year follow-up. Spine (Phila Pa 1976) 37 : 489-500, 2012

8. Choi HY, Hyun SJ, Kim KJ, Jahng TA, Kim HJ : Effectiveness and safety of tranexamic acid in spinal deformity surgery. J Korean Neurosurg Soc
$60: 75-81,2017$

9. Choi HY, Hyun SJ, Kim KJ, Jahng TA, Kim HJ : Surgical and radiographic outcomes after pedicle subtraction osteotomy according to surgeon's experience. Spine (Phila Pa 1976) 42 : E795-E801, 2017

10. Clark AJ, Garcia RM, Keefe MK, Koski TR, Rosner MK, Smith JS, et al. : Results of the AANS membership survey of adult spinal deformity knowledge: impact of training, practice experience, and assessment of potential areas for improved education: clinical article. J Neurosurg Spine 21 : 640-647, 2014

11. Daniels AH, Ames CP, Smith JS, Hart RA : Variability in spine surgery procedures performed during orthopaedic and neurological surgery residency training: an analysis of ACGME case log data. J Bone Joint Surg Am 96 : e196, 2014

12. Emami A, Deviren V, Berven S, Smith JA, Hu SS, Bradford DS : Outcome and complications of long fusions to the sacrum in adult spine deformity: luque-galveston, combined iliac and sacral screws, and sacral fixation. Spine (Phila Pa 1976) 27 : 776-786, 2002

13. Han S, Hyun SJ, Kim KJ, Jahng TA, Kim HJ : Comparative study between cobalt chrome and titanium alloy rods for multilevel spinal fusion: proximal junctional kyphosis more frequently occurred in patients having cobalt chrome rods. World Neurosurg 103 : 404-409, 2017

14. Hyun SJ, Han S, Kim KJ, Jahng TA, Kim YJ, Rhim SC, et al. : Adolescent idiopathic scoliosis surgery by a neurosurgeon: learning curve for neurosurgeons. World neurosurgery 110 : e129-e134, 2018

15. Hyun SJ, Lee BH, Park JH, Kim KJ, Jahng TA, Kim HJ : Proximal junctional kyphosis and proximal junctional failure following adult spinal deformity surgery. Korean J Spine 14 : 126-132, 2017

16. Hyun SJ, Lenke LG, Kim YC, Koester LA, Blanke KM : Comparison of standard 2-rod constructs to multiple-rod constructs for fixation across 3-column spinal osteotomies. Spine (Phila Pa 1976) 39 : 1899-1904, 2014

17. Hyun SJ, Rhim SC : Clinical outcomes and complications after pedicle subtraction osteotomy for fixed sagittal imbalance patients : a long-term follow-up data. J Korean Neurosurg Soc 47 : 95-101, 2010

18. Kim HJ, Lenke LG, Shaffrey $\mathrm{Cl}$, Van Alstyne EM, Skelly AC : Proximal junctional kyphosis as a distinct form of adjacent segment pathology after spinal deformity surgery: a systematic review. Spine (Phila Pa 1976) 37 (22 Suppl) : S144-S164, 2012

19. Kim YJ, Hyun SJ, Cheh G, Cho SK, Rhim SC : Decision making algorithm for adult spinal deformity surgery. J Korean Neurosurg Soc 59 : 327333, 2016

20. Konczalik W, Elsayed S, Boszczyk B : Experience of a fellowship in spinal surgery: a quantitative analysis. Eur Spine J 23 Suppl 1 : S40-S54, 2014

21. Kriss TC, Kriss VM : History of the operating microscope: from magnifying glass to microneurosurgery. Neurosurgery 42 : 899-907; discussion 907-908, 1998

22. Kwon JW, Hyun SJ, Han SH, Kim KJ, Jahng TA : Pyogenic vertebral osteomyelitis: clinical features, diagnosis, and treatment. Korean J Spine $14: 27-34,2017$

23. Lapp MA, Bridwell KH, Lenke LG, Daniel Riew K, Linville DA, Eck KR, et 
al. : Long-term complications in adult spinal deformity patients having combined surgery a comparison of primary to revision patients. Spine (Phila Pa 1976) 26 : 973-983, 2001

24. Lee BH, Hyun SJ, Kim KJ, Jahng TA, Kim YJ, Kim HJ : Clinical and radiological outcomes of posterior vertebral column resection for severe spinal deformities. J Korean Neurosurg Soc 61 : 251-257, 2018

25. Lee BH, Hyun SJ, Park JH, Kim KJ : Single stage posterior approach for total resection of presacral giant schwannoma: a technical case report. Korean J Spine $14:$ : 89-92, 2017

26. Lee CH, Chung CK, Jang JS, Kim SM, Chin DK, Lee JK : 'Lumbar degenerative kyphosis' is not byword for degenerative sagittal imbalance: time to replace a misconception. J Korean Neurosurg Soc 60 : 125-129, 2017

27. Makhni MC, Shillingford JN, Laratta JL, Hyun SJ, Kim YJ : Restoration of sagittal balance in spinal deformity surgery. J Korean Neurosurg Soc 61 : 167-179, 2018

28. Park YS, Hyun SJ, Kim KJ, Jahng TA : Multiple intradural disc herniations masquerading as intradural extramedullary tumors: a case report and review of the literature. Korean J Spine $13:$ 30-32, 2016

29. Park YS, Hyun SJ, Kim KJ, Jahng TA : Plasmacytoma to the axis mimicking metastatic paraganglioma: circumferential reconstruction via posterior approach. Korean J Spine 12 : 283-286, 2015

30. Pejrona M, Ristori G, Villafañe $J H$, Pregliasco FE, Berjano P : Does specialty matter? A survey on 176 Italian neurosurgeons and orthopedic spine surgeons confirms similar competency for common spinal conditions and supports multidisciplinary teams in comprehensive and complex spinal care. Spine J 18 : 1498-1503, 2018

31. Potter BK, Lenke LG, Kuklo TR : Prevention and management of iatrogenic flatback deformity. J Bone Joint Surg Am 86-A : 1793-1808,
2004

32. Schlenk RP, Stewart T, Benzel EC : The biomechanics of iatrogenic spinal destabilization and implant failure. Neurosurg Focus 15 : E2, 2003

33. Schwab F, Dubey A, Gamez L, El Fegoun AB, Hwang K, Pagala M, et al. : Adult scoliosis: prevalence, SF-36, and nutritional parameters in an elderly volunteer population. Spine (Phila Pa 1976) 30 : 1082-1085, 2005

34. Schwab F, Lafage V, Farcy JP, Bridwell K, Glassman S, Ondra S, et al. : Surgical rates and operative outcome analysis in thoracolumbar and lumbar major adult scoliosis: application of the new adult deformity classification. Spine (Phila Pa 1976) 32: 2723-2730, 2007

35. Seicean A, Alan N, Seicean S, Neuhauser D, Benzel EC, Weil RJ : Surgeon specialty and outcomes after elective spine surgery. Spine (Phila Pa 1976) 39 : 1605-1613, 2014

36. Seyal M, Mull B : Mechanisms of signal change during intraoperative somatosensory evoked potential monitoring of the spinal cord. J Clin Neurophysiol 19 : 409-415, 2002

37. Shapiro GS, Taira G, Boachie-Adjei 0 : Results of surgical treatment of adult idiopathic scoliosis with low back pain and spinal stenosis: a study of long-term clinical radiographic outcomes. Spine (Phila Pa 1976) 28 : 358-363, 2003

38. Slosar PJ : Indications and outcomes of reconstructive surgery in chronic pain of spinal origin. Spine (Phila Pa 1976) 27 : 2555-2562; discussion 2563, 2002

39. Takahashi S, Delécrin J, Passuti N : Surgical treatment of idiopathic scoliosis in adults: an age-related analysis of outcome. Spine (Phila Pa 1976) 27 : 1742-1748, 2002

40. Uluçc K, Kujoth GC, Baskaya MK : Operating microscopes: past, present, and future. Neurosurg Focus 27 : E4, 2009 